\title{
Climatological characteristics of raindrop size distributions in Busan, Republic of Korea
}

\author{
S.-H. Suh ${ }^{1}$, C.-H. You ${ }^{2}$, and D.-I. Lee ${ }^{1,2}$ \\ ${ }^{1}$ Department of Environmental Atmospheric Sciences, Pukyong National University, Daeyeon campus 45, Yongso-ro, \\ Namgu, Busan 608-737, Republic of Korea \\ ${ }^{2}$ Atmospheric Environmental Research Institute, Daeyeon campus 45, Yongso-ro, Namgu, Busan 608-737, Republic of Korea \\ Correspondence to: C.-H. You (youch@pknu.ac.kr)
}

Received: 17 March 2015 - Published in Hydrol. Earth Syst. Sci. Discuss.: 20 April 2015

Revised: 8 December 2015 - Accepted: 20 December - Published: 18 January 2016

\begin{abstract}
Raindrop size distribution (DSD) characteristics within the complex area of Busan, Republic of Korea $\left(35.12^{\circ} \mathrm{N}, 129.10^{\circ} \mathrm{E}\right)$, were studied using a Precipitation Occurrence Sensor System (POSS) disdrometer over a 4-year period from 24 February 2001 to 24 December 2004. Also, to find the dominant characteristics of polarized radar parameters, which are differential radar reflectivity $\left(Z_{\mathrm{dr}}\right)$, specific differential phase $\left(K_{\mathrm{dp}}\right)$ and specific attenuation $\left(A_{\mathrm{h}}\right)$, Tmatrix scattering simulation was applied in the present study. To analyze the climatological DSD characteristics in more detail, the entire period of recorded rainfall was divided into 10 categories not only covering different temporal and spatial scales, but also different rainfall types. When only convective rainfall was considered, mean values of mass-weighted mean diameter $\left(D_{\mathrm{m}}\right)$ and normalized number concentration $\left(N_{\mathrm{w}}\right)$ values for all these categories converged around a maritime cluster, except for rainfall associated with typhoons. The convective rainfall of a typhoon showed much smaller $D_{\mathrm{m}}$ and larger $N_{\mathrm{w}}$ compared with the other rainfall categories.

In terms of diurnal DSD variability, we analyzed maritime (continental) precipitation during the daytime (DT) (nighttime, NT), which likely results from sea (land) wind identified through wind direction analysis. These features also appeared in the seasonal diurnal distribution. The DT and NT probability density function (PDF) during the summer was similar to the PDF of the entire study period. However, the DT and NT PDF during the winter season displayed an inverse distribution due to seasonal differences in wind direction.
\end{abstract}

\section{Introduction}

Raindrop size distribution (DSD) is controlled by the microphysical processes of rainfall, and therefore it plays an important role in development of the quantitative precipitation estimation (QPE) algorithms based on forward scattering simulations of radar measurements (Seliga and Bringi, 1976). DSD data accurately reflect local rainfall characteristics within an observation area (You et al., 2014). Many DSD models have been developed to characterize spatial-temporal differences in DSDs under various atmospheric conditions (Ulbrich, 1983). Marshall and Palmer (1948) developed an exponential DSD model using DSD data collected by a filter paper technique $\left(N(D)=8 \times 10^{3} \exp \left(-4.1 R^{-0.21} D\right)\right.$ in $\mathrm{m}^{-3} \mathrm{~mm}^{-1} D$ in $\mathrm{mm}$ and $R$ in $\left.\mathrm{mm} \mathrm{h}^{-1}\right)$. In subsequent studies, a lognormal distribution was assumed to overcome the problem of exponential DSD mismatching with real data (Mueller and Sims, 1966; Levin, 1971; Markowitz, 1976; Feingold and Levin, 1986).

To further investigate natural DSD variations, U1brich (1983) developed a gamma DSD that permitted one to change the dimension of the intercept parameter $\left(N_{0}\right.$ in $\left.\mathrm{m}^{-3} \mathrm{~mm}^{-1-\mu}\right)$ with $N(D)=N_{0} D^{\mu} \exp (-\Lambda D)$. In addition, to enable the quantitative analysis of different rainfall events, the development of a normalized gamma DSD model that accounted for the independent distribution of DSD from the disdrometer channel interval enabled a better representation of the actual DSD (Willis, 1984; Dou et al., 1999; Testud et al., 2001).

DSDs depend on the rainfall type, geographical and atmospheric conditions, and observation time. Also, these are 
closely linked to microphysical characteristics that control rainfall development mechanisms. In the case of stratiform rainfall, raindrops grow by the accretion mechanism because of the relatively long residence time in weak updraft condition, in which almost all water droplets are changed to ice particles. With time, the ice particles grow sufficiently and fall to the ground. The raindrop size of stratiform rainfall observed at the ground level is larger than that of convective rainfall for a same rainfall intensity due to the resistance of the ice particles to break-up mechanisms. In contrast to stratiform rainfall, convective rainfall raindrops grow by the collision-coalescence mechanism associated with relatively strong vertical wind speeds and short residence time in the cloud. Fully grown raindrops of maritime precipitation are smaller in diameter than those in stratiform rainfall due to the break-up mechanism in the case of the same rainfall rate (Mapes and Houze Jr., 1993; Tokay and Short, 1996). Convective rainfall can be classified into two types based on the origin and direction of movement. Rainfall systems occurring over ocean and land are referred to as maritime and continental rainfall, respectively (Göke et al., 2007). Continental rainfall is related to a cold-rain mechanism whereby raindrops grow in the form of ice particles. In contrast, maritime rainfall is related to a warm-rain mechanism whereby raindrops grow by the collision-coalescence mechanism. Therefore, the mass-weighted drop diameter $\left(D_{\mathrm{m}}\right)$ of continental rainfall observed on the ground is larger than that of maritime rainfall, and a smaller normalized intercept parameter $\left(N_{\mathrm{w}}\right)$ is observed in continental rainfall (Bringi et al., 2003).

Specific heat is a major climatological feature that creates differences between DSDs in maritime and continental regions. These two regions have different thermal capacities, and thus different temperature variations have occurred with time. The surface temperature of the ocean changes slowly because of the higher thermal capacity compared with land, while the continental regions that have a comparatively lower thermal capacity show greater diurnal temperature variability. Sea winds generally occur from afternoon to early evening when the temperature gradient between the sea and land becomes negative, which is the opposite gradient in the daytime (DT). In coastal regions, the land and sea wind effect causes a pronounced difference between the DT and nighttime (NT) DSD characteristics. Also, when mountains are located near the coast, the difference is intensified by the effect of mountain and valley winds (Qian, 2008).

In the present study, we analyzed a 4-year data set spanning from 2001 to 2004, collected from Busan, Republic of Korea $\left(35.12^{\circ} \mathrm{N}, 129.10^{\circ} \mathrm{E}\right)$, using a Precipitation Occurrence Sensor System (POSS) disdrometer, to investigate the characteristics of DSDs in Busan, Republic of Korea, which consist of a complex mid-latitude region comprising both land and ocean. To quantify the effect of land and sea wind on these characteristics, we also analyzed diurnal variations in DSDs. The remainder of the paper is organized as follows. In Sect. 2 we review the normalized gamma model and explain the DSD quality control method and the classification of rainfall. In Sect. 3 we report the results of DSD analysis with respect to stratiform/convective and continental/maritime rainfall, and discuss diurnal variations. Finally, a summary of the results and the main conclusions are presented in Sect. 4.

\section{Data and methods}

\subsection{Normalized gamma DSD}

DSDs are defined by $N(D)=N_{0} \exp (-\Lambda D)\left(\mathrm{m}^{-3} \mathrm{~mm}^{-1}\right)$ and reflect the microphysical characteristics of rainfall using the number concentration of raindrops $(N(D))$. Also, DSDs are able to calculate the many kinds of parameters that show the dominant feature of raindrops. Normalization is used to define the DSD and to solve the non-independence of each DSD parameter (Willis, 1984; Dou et al., 1999; Testud et al., 2001). Furthermore, a normalized gamma DSD enables the quantitative comparison for rainfall cases regardless of timescale and rain rate. Here, we use the DSD model designed by Testud et al. (2001):

$N(D)=N_{\mathrm{w}} f(\mu)\left(\frac{D}{D_{\mathrm{m}}}\right)^{\mu} \exp \left[-(4+\mu) \frac{D}{D_{\mathrm{m}}}\right]$,

where $D$ is the volume-equivalent spherical raindrop diameter $(\mathrm{mm})$, and $f(\mu)$ is defined using the DSD model shape parameter $(\mu)$ and gamma function $(\Gamma)$ as follows:

$f(\mu)=\frac{6}{4^{4}} \frac{(4+\mu)^{\mu+4}}{\Gamma(\mu+4)}$.

From the value of $N(D)$, the median volume diameter $\left(D_{0}\right.$ in $\mathrm{mm}$ ) can be obtained as follows:

$\int_{0}^{D_{0}} D^{3} N(D) \mathrm{d} D=\frac{1}{2} \int_{0}^{D_{\max }} D^{3} N(D) \mathrm{d} D$.

Mass-weighted mean diameter $\left(D_{\mathrm{m}}\right.$ in $\left.\mathrm{mm}\right)$ is calculated as the ratio of the fourth to the third moment of the DSD:

$D_{\mathrm{m}}=\frac{\int_{0}^{D_{\max }} D^{4} N(D) \mathrm{d} D}{\int_{0}^{D_{\max }} D^{3} N(D) \mathrm{d} D}$.

The normalized intercept parameter $\left(N_{\mathrm{W}}\right.$ in $\left.\mathrm{m}^{-3} \mathrm{~mm}^{-1}\right)$ is calculated as follows:

$N_{\mathrm{w}}=\frac{4^{4}}{\pi \rho_{\mathrm{w}}}\left(\frac{\mathrm{LWC}}{D_{\mathrm{m}}^{4}}\right)$.

The shape of the DSD is calculated as the ratio of $D_{\mathrm{m}}$ to the standard deviation (SD) of $D_{\mathrm{m}}\left(\sigma_{\mathrm{m}}\right.$ in mm) (Ulbrich and Atlas, 1998; Bringi et al., 2003; Leinonen et al., 2012):

$\sigma_{\mathrm{m}}=\left[\frac{\int_{0}^{D_{\max }} D^{3}\left(D-D_{\mathrm{m}}\right)^{2} N(D) \mathrm{d} D}{\int_{0}^{D_{\max }} D^{3} N(D) \mathrm{d} D}\right]^{\frac{1}{2}}$. 
In addition, $\sigma_{\mathrm{m}} / D_{\mathrm{m}}$ is related to $\mu$ as follows:

$\frac{\sigma_{\mathrm{m}}}{D_{\mathrm{m}}}=\frac{1}{(4+\mu)^{1 / 2}}$.

Liquid water content (LWC in $\mathrm{g} \mathrm{m}^{-3}$ ) can be defined from the estimated DSD:

$\mathrm{LWC}=\frac{\pi}{6} \rho_{\mathrm{w}} \int_{0}^{D_{\max }} D^{3} N(D) \mathrm{d} D$,

where $\rho_{\mathrm{W}}$ is the water density $\left(\mathrm{g} \mathrm{m}^{-3}\right)$, and it is assumed to be $1 \times 10^{6} \mathrm{~g} \mathrm{~m}^{-3}$ for a liquid. Similarly, the rainfall rate $(R$ in $\mathrm{mm} \mathrm{h}^{-1}$ ) can be defined as follows:

$R=\frac{3.6}{10^{3}} \frac{\pi}{6} \int_{0}^{D_{\max }} v(D) D^{3} N(D) \mathrm{d} D$,

where the value of factor $3.6 \times 10^{-3}$ is the unit conversion that converts the mass flux unit $\left(\mathrm{mg} \mathrm{m}^{-2} \mathrm{~s}^{-1}\right)$ to the common unit $\left(\mathrm{mm} \mathrm{h}^{-1}\right)$ for convenience. $v(D)\left(\mathrm{m} \mathrm{s}^{-1}\right)$ is the terminal velocity for each raindrop size. The relationship between $v(D)$ and $D(\mathrm{~mm})$ is given by Atlas et al. (1973), who developed an empirical formula based on the data reported by Gunn and Kinzer (1949):

$v(D)=9.65-10.3 \exp [-0.6 D]$.

\subsection{Quality control of POSS data}

POSS is used to measure the number of raindrops within the diameter range of $0.34-5.34 \mathrm{~mm}$, using bistatic, continuouswave X-band Doppler radar $(10.525 \mathrm{GHz})$ across 34 channels (Fig. 1; Sheppard and Joe, 2008). To estimate DSDs, the Doppler power density spectrum is calculated as follows:

$S(f)=$

$\int_{D_{\min }}^{D_{\max }} N\left(D_{\mathrm{m}}\right) V\left(D_{\mathrm{m}}, \rho, h, w\right) \bar{S}\left(f, D_{\mathrm{m}}, \rho, h, w\right) \mathrm{d} D_{\mathrm{m}}$,

where $S(f)$ means Doppler spectrum power density, $V\left(D_{\mathrm{m}} \rho h, w\right) \bar{S}\left(f, D_{\mathrm{m}} \rho h, w\right)$ means weighting function of $S(f), \bar{S}$ is the mean of $S(f), \rho$ is density of precipitation distribution, $h$ is the shape of precipitation distribution, $w\left(\mathrm{~m} \mathrm{~s}^{-1}\right)$ is wind speed, $V(x)$ is sample volume, and the symbol " $x$ " means arbitrary parameters that affect the sampling volume. The Doppler power density spectrum has a resolution of $16 \mathrm{~Hz}$, and terminal velocity $\left(v_{\mathrm{t}}\right)$ has a resolution of $0.24 \mathrm{~m} \mathrm{~s}^{-1}$. Transmitter and receiver skewed about $20^{\circ}$ toward each other, and the cross point of the signal is located over $34 \mathrm{~cm}$ from the transmitter-receiver. The transmitter-receiver toward the upper side detects $N(D)$ in $V(x)$ (Sheppard, 1990). Also, Sheppard (1990) and Sheppard and Joe (1994) noted some shortcomings as the overestimation of small drops at horizontal wind was larger than $6 \mathrm{~m} \mathrm{~s}^{-1}$. However, in the present study, the quality control of POSS for wind effects was not considered, because it lies

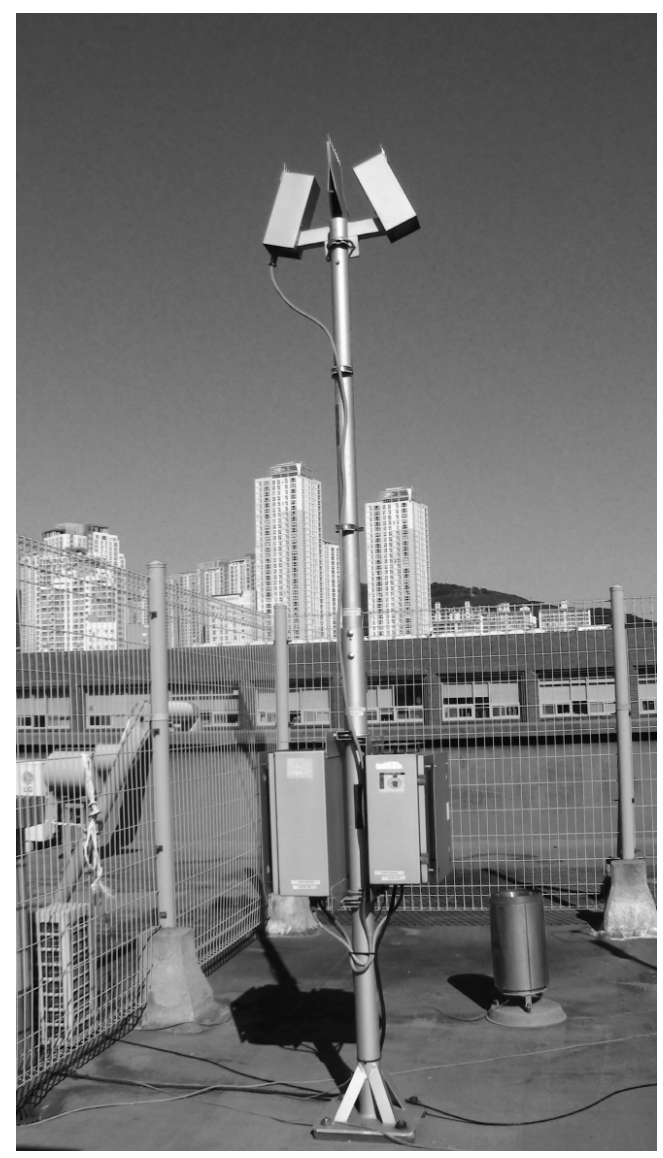

Figure 1. Photograph of the POSS instrument used in this research.

Table 1. Specification of the POSS disdrometer.

\begin{tabular}{ll}
\hline Specifications & Detail \\
\hline Manufacturer & ANDREW CANADA INC \\
Module & PROCESSOR \\
Model number & POSS-F01 \\
Nominal power & $100 \mathrm{~mW}$ \\
Bandwidth & Single frequency \\
Emission & $43 \mathrm{~mW}$ \\
Pointing direction & $20^{\circ}$ (to the vertical side) \\
Antenna & Rectangular pyramidal horns \\
Range of sample area & $<2 \mathrm{~m}$ \\
Wavelength & $10.525 \mathrm{GHz} \pm 15 \mathrm{GHz}$ \\
Physical dimension & $277 \times 200 \times 200 \mathrm{~cm}^{3}$ \\
Net weight & Approximately $110 \mathrm{~kg}$ \\
\hline
\end{tabular}

beyond the scope of this work. Detailed specifications and measurement ranges and raindrop sizes for each observation channel of the POSS disdrometer are summarized in Table 1.

A POSS disdrometer has been operating in Busan, Republic of Korea $\left(35.12^{\circ} \mathrm{N}, 129.10^{\circ} \mathrm{E}\right)$, along with other atmospheric instruments, the locations of which are shown in Fig. 2. Estimating raindrop diameter correctly is challenging, 


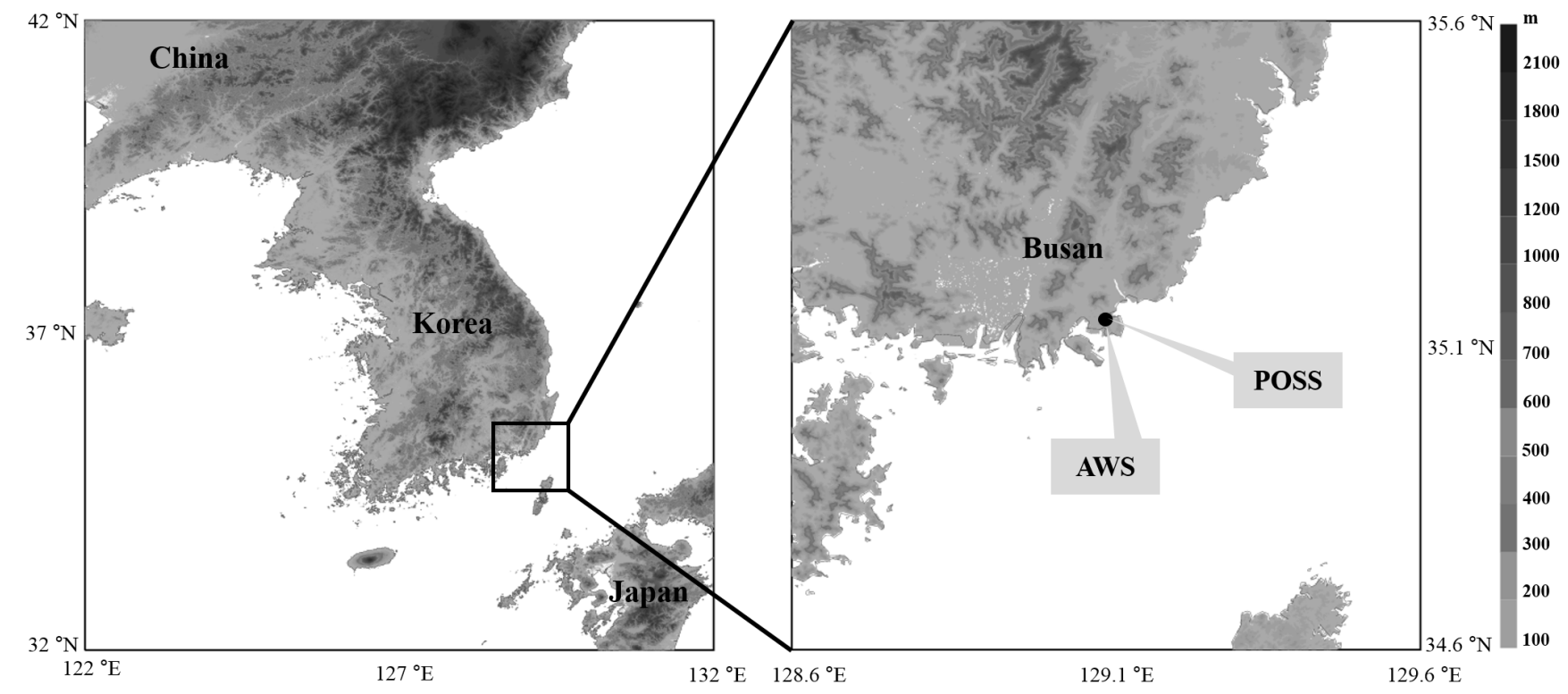

Figure 2. Locations of the POSS and the AWS rain gauge installed in Busan, Republic of Korea.

and care should be taken to ensure reliable data are collected. We performed the following quality controls to optimize the accuracy of the disdrometer estimates. (i) Non-liquid type event data (e.g., snow, hail) detected by POSS were excluded by routine observation and the surface weather chart provided by the Korea Meteorological Administration (KMA). (ii) DSD spectra in which drops were not found in at least five consecutive channels were removed as non-atmospheric. (iii) Only data recorded in more than 10 complete channels were considered. (iv) To compensate for the reduced capability to detect raindrops smaller than $1 \mathrm{~mm}$ when $R>200 \mathrm{~mm} \mathrm{~h}^{-1}$ (as recorded by the disdrometer), data for $R>200 \mathrm{~mm} \mathrm{~h}^{-1}$ were not included in the analyses, even though the number of samples was only 64 for the entire period. (v) To eliminate wind and acoustic noise, data collected when $R<0.1 \mathrm{~mm} \mathrm{~h}^{-1}$ are removed (Tokay and Short, 1996).

After performing all quality control procedures, 99388 spectra were left from the original data (166682) for $1 \mathrm{~min}$ temporal resolution. The accumulated rainfall amount from POSS during the entire period was $4261.49 \mathrm{~mm}$. To verify the reliability of the POSS data, they were compared with data collected by a $0.5 \mathrm{~mm}$ tipping bucket rain gauge at an automatic weather system (AWS) located $\sim 368 \mathrm{~m}$ from the POSS (Fig. 3).

\subsection{Radar parameters}

First, the radar reflectivity factor $\left(z\right.$ in $\left.\mathrm{mm}^{6} \mathrm{~m}^{-3}\right)$ and nonpolarized radar reflectivity ( $Z$ in dBZ) were computed using the DSD data collected by POSS, as follows:

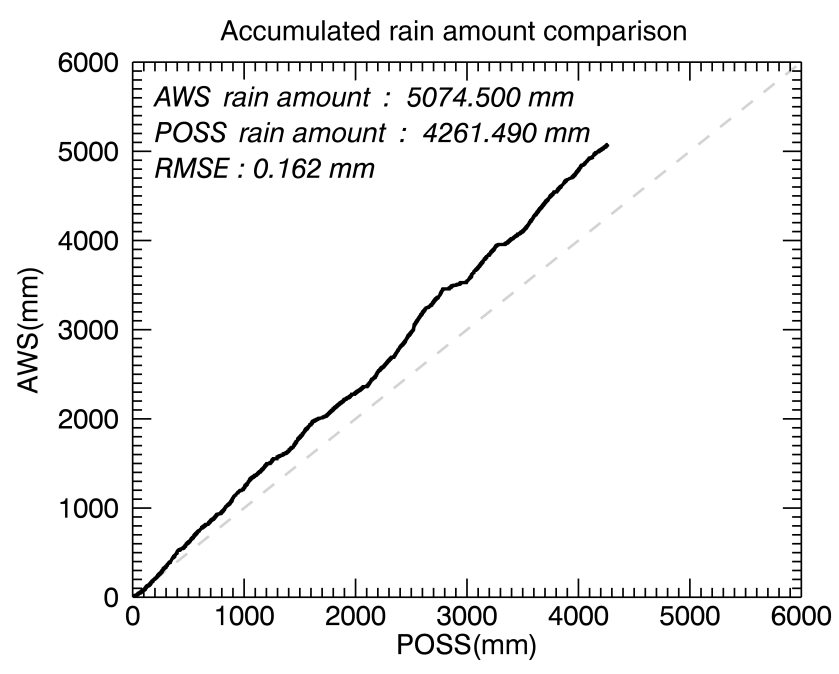

Figure 3. Comparison of the recorded rainfall amounts between the POSS and AWS instruments.

$z=\int_{0}^{D_{\max }} D^{6} N(D) \mathrm{d} D$,
$Z=10 \log _{10}(z)$

The T-matrix method used in this study was initially proposed by Waterman $(1965,1971)$ to calculate electromagnetic scattering by single non-spherical raindrops. The adaptable parameters for this calculation are frequency, temperature, hydrometeor types, raindrop canting angle, and axis ratio $(\gamma)$, and explained the following sentences. Axis ratios of raindrops differ with atmospheric conditions and rainfall type. To derive the drop shape relation from the drop diame- 
ter, we applied the results of numerical simulations and wind tunnel tests employing a fourth-order polynomial equation, as in many previous studies (Beard and Chuang, 1987; Pruppacher and Beard, 1970; Andsager et al., 1999; Brandes et al., 2002). The axis ratio relation used in the present study is a combination of those from Andsager et al. (1999) and Beard and Chuang (1987) for three raindrop size ranges (Bringi et al., 2003).

The raindrop axis ratio relation of Andsager et al. (1999) is applied in the range of $1<D(\mathrm{~mm})<4$, as follows:

$\gamma=1.012+0.01445 \times 10^{-1} D-0.01028 \times 10^{-2} D^{2}$.

The drop-shaped relation of Beard and Chuang (1987) is applied in the range of $D<1 \mathrm{~mm}$ and $D>4 \mathrm{~mm}$, as follows:

$$
\begin{aligned}
\gamma & =1.0048+0.0057 \times 10^{-1} D-2.628 \times 10^{-2} \\
& \times D^{2}+3.682 \times 10^{-3} D^{3}-1.677 \times 10^{-4} D^{4}
\end{aligned}
$$

We assumed SD and the mean canting angle of raindrops to be 7 and $0^{\circ}$, respectively. The refractive indices of liquid water at $20^{\circ} \mathrm{C}$ were used (Ray, 1972). Also, the condition of frequency for electromagnetic wave of radar is $2.85 \mathrm{GHz}(\mathrm{S}$ band). We calculated dual polarized radar parameters based on these conditions. The parameters of differential reflectivity $\left(Z_{\mathrm{dr}}\right.$ in $\left.\mathrm{dB}\right)$, specific differential phase $\left(K_{\mathrm{dp}}\right.$ in deg $\left.\mathrm{km}^{-1}\right)$, and attenuation $\left(A_{\mathrm{h}}\right.$ in $\left.\mathrm{dB} \mathrm{km}^{-1}\right)$ using DSD data were calculated and analyzed.

\subsection{Classification of rainfall types and rainfall events}

Rainfall systems can be classified as stratiform or convective in nature, via analysis of the following microphysical characteristics: (i) DSD, using relationships between $N_{0}$ and $R$ $\left(N_{0}>4 \times 10^{9} R^{-4.3}\right.$ in $\mathrm{m}^{-3} \mathrm{~mm}^{-1}$ is considered to be convective rainfall, Tokay and Short, 1996; Testud et al., 2001); (ii) $Z$, where, according to Gamache and Houze Jr. (1982), a rainfall system that displays radar reflectivity larger than $38 \mathrm{dBZ}$ is considered to be convective; and (iii) $R$, where an average value larger than $0.5 \mathrm{~mm}$ per $5 \mathrm{~min}$ is considered to be convective rainfall (Johnson and Hamilton, 1988). Alternatively, rainfall that has $1 \mathrm{~min} R>5(0.5) \mathrm{mm} \mathrm{h}^{-1}$ and a SD of $\mathrm{R}>(<) 1.5 \mathrm{~mm} \mathrm{~h}^{-1}$ is considered to be of the convective (stratiform) type (Bringi et al., 2003). The rainfall classification method proposed by Bringi et al. (2003) is applied in the present study.

It is necessary to categorize different rainfall systems because their microphysical characteristics show great variation depending on the type of rainfall, as well as the type of rainfall event, e.g., typhoon, Changma, heavy rainfall and seasonally discrete rainfall. To investigate the temporal variation in DSDs, we analyzed daily and seasonal DSDs. Likewise, to investigate diurnal variability in DSD, DT, and NT data were considered by using the sunrise and sunset time in Busan (provided by the Korea Astronomy and Space Science Institute (KASI)). In the middle latitudes, and includ- ing Busan, the timings of sunrise and sunset vary due to solar culminating height. The earliest and latest sunrise (sunset) time of the entire period is 05:09 KST (17:12 KST) and 07:33 KST (19:42 KST), respectively. DT (NT) is defined as the period from the latest sunrise (sunset) time to the earliest sunset (sunrise) time for the unity of classification of each time group (Table 2).

To analyze the predominant characteristics of DSDs for typhoon rainfall, nine typhoon events were selected from throughout the entire study period, which is summarized in Table 2 .

This study utilizes KMA rainfall warning regulations to identify heavy rainfall events. The KMA issues a warning if the accumulated rain amount is expected to be $>70 \mathrm{~mm}$ within a $6 \mathrm{~h}$ period, or $>110 \mathrm{~mm}$ within a $12 \mathrm{~h}$ period. Rainfall events classified as Changma and typhoon were not included in the classification "heavy rainfall".

Changma is the localized rainfall system or rainy season that is usually present over the Korean Peninsula between mid-June and mid-July, which is similar to the Meiyu (China) or Baiu (Japan). The selected dates and periods of each rainfall category are summarized in Table 2.

\section{Results}

\subsection{DSD and radar parameters}

Figure 4 shows the probability density function (PDF) and cumulative distribution function (CDF) of DSDs and radar parameters with respect to the entire, stratiform and convective rainfall. The PDFs of DSD and radar parameters were calculated using the non-parameterization kernel estimation to identify the dominant distribution of each parameter recorded in Busan. Non-parameterization kernel estimation was also used to identify continuous distributions of DSDs. The PDF of stratiform rainfall is more similar to that of the data set for the entire analysis period due to the dominant contribution of stratiform rainfall (about $62.93 \%$ ) to the overall rainfall than that of convective rainfall. However, the PDF for convective rainfall is significantly different from that of the entire analysis period, and as the convective rainfall contributes only $6.11 \%$ of the overall rainfall (Table 3). When $\mu<0$, the distribution of $\mu$ for convective rain has more values of PDF than that for stratiform rain (Fig. 4a). Alternatively, the frequency of $\mu$ for stratiform rainfall is higher than that of convective rainfall when $0<\mu<5$. The value of $\mu$ for convective rainfall is higher than that for stratiform rainfall because the break-up mechanism would increase the number concentration of small raindrops. The number concentrations of mid-size raindrops increased due to the decrease in the number concentration of relatively large raindrops (Hu and Srivastava, 1995; Sauvageot and Lacaux, 1995). However, we observed a higher frequency of 

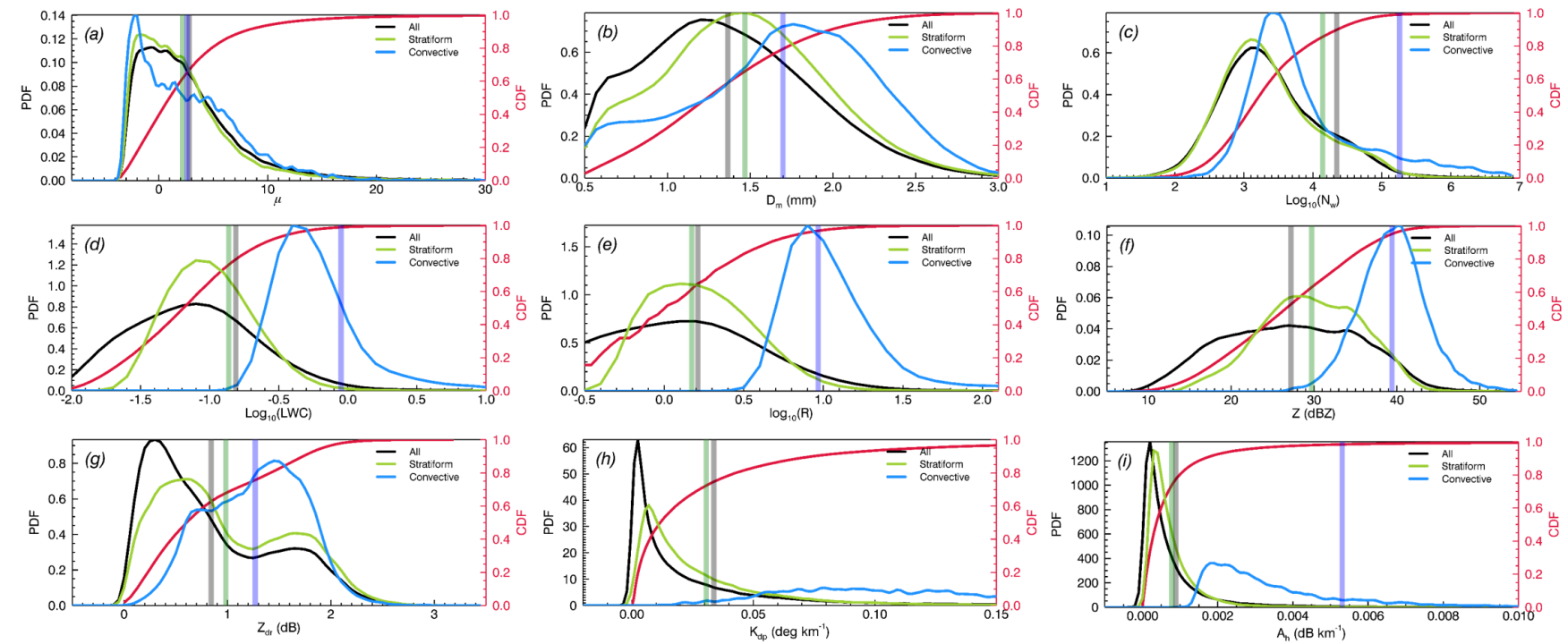

Figure 4. PDF and CDF for (a) $\mu$, (b) $D_{\mathrm{m}}$, (c) $\log _{10}\left(N_{\mathrm{w}}\right)$, (d) $\log _{10}(R)$, (e) $\log _{10}(\mathrm{LWC}),(\mathbf{f}) Z$, (g) $Z_{\mathrm{dr}}$, (h) $K_{\mathrm{dp}}$, and (i) $A_{\mathrm{h}}$ for the entire rainfall data set (solid black line), stratiform rainfall (solid green line), and convective rainfall (solid blue line). The solid red line represents the CDF for the entire rainfall data set. The solid vertical line represents the mean value of each type.

Table 2. Designated date with respect to the source of rainfall.

\begin{tabular}{|c|c|c|c|c|}
\hline \multirow{3}{*}{$\begin{array}{l}\text { Rainfall category } \\
\text { Typhoon }\end{array}$} & \multicolumn{4}{|c|}{ Period } \\
\hline & 2001 & 2002 & 2003 & 2004 \\
\hline & - & $\begin{array}{l}\text { 5-6 Jul, } \\
31 \text { Aug }\end{array}$ & $\begin{array}{l}29 \text { May, } 19 \text { Jun, } 7 \text { Aug, } \\
\text { 11-12 Sep }\end{array}$ & $\begin{array}{l}20 \text { Jun, } 19 \\
\text { Aug, } \\
6 \text { Sep }\end{array}$ \\
\hline Changma & $\begin{array}{l}\text { 18-19 Jun, 23-26 Jun, } \\
\text { 29-30 Jun, 1 Jul, } \\
\text { 5-6 Jul, 11-14 Jul }\end{array}$ & $\begin{array}{l}\text { 23-25 Jun, } 30 \text { Jun, } \\
1-2 \text { Jul }\end{array}$ & $\begin{array}{l}\text { 12-14 Jun, } 23 \text { Jun, } 27 \\
\text { Jun, } 30 \text { Jun, } 1 \text { Jul, } \\
\text { 3-15 Jul }\end{array}$ & 11-14 Jul \\
\hline Heavy rainfall & \multicolumn{4}{|c|}{15 Apr 2002, 20:13 KST to 16 Apr 2002, 06:29 KST } \\
\hline \multirow[t]{2}{*}{ Seasonal } & Spring & Summer & Autumn & Winter \\
\hline & Mar to May & Jun to Aug & Sep to Nov & Dec to Feb \\
\hline \multirow[t]{2}{*}{ Diurnal } & \multicolumn{2}{|c|}{$\begin{array}{c}\text { DT (KST) } \\
07 \cdot 33-17 \cdot 12\end{array}$} & \multicolumn{2}{|c|}{ NT (KST) } \\
\hline & \multicolumn{2}{|c|}{$07: 33-17: 12$} & \multicolumn{2}{|c|}{ 19:42-05:09 } \\
\hline
\end{tabular}

convective rainfall than stratiform rainfall in the negative $\mu$ range.

The PDF of $D_{\mathrm{m}}$ displays a peak around 1.2 and $1.4 \mathrm{~mm}$ for stratiform rainfall and the entire rainfall data set, respectively. We note that a gentle peak exists around $0.7 \mathrm{~mm}$ for both stratiform and convective rainfall data sets (Fig. 4b). These features are similar to the distribution of $D_{\mathrm{m}}$ observed in a high-latitude region at Järvenpää, Finland (Fig. 4 of Leinonen et al., 2012). For $D_{\mathrm{m}}$ values $>1.7 \mathrm{~mm}$, the PDF for convective rainfall is higher than stratiform rainfall. Accordingly, the value of DSD for stratiform rainfall is higher than that of convective rainfall when $D_{\mathrm{m}}<1.7 \mathrm{~mm}$. Generally, stratiform rainfall that develops by the cold rain process displays weaker upward winds and less efficient break- up of raindrops. Therefore, in the same rainfall rate, stratiform rainfall tends to produce larger raindrops than convective rainfall, which develops by the warm rain process. However, the average $D_{\mathrm{m}}$ values for convective and stratiform rain for the entire period are approximately 1.45 and $1.7 \mathrm{~mm}$, respectively. In short, $D_{\mathrm{m}}$ is proportional to $R$ regardless of rainfall type. This finding is consistent with the results of Atlas et al. (1999), who found that the $D_{\mathrm{m}}$ of convective rainfall is larger than that of stratiform rainfall on Kapingamarangi, Micronesia.

The PDF of $\log _{10}\left(N_{\mathrm{w}}\right)$ for the entire rainfall data set was evenly distributed between 1.5 and 5.5 , with a peak at $N_{\mathrm{w}}=3.3$ (Fig. 4c). The PDF of $\log _{10}\left(N_{\mathrm{w}}\right)$ for stratiform rainfall is rarely $>5.5$, while for convective rainfall it 
Table 3. Rainfall rate for each rainfall category and the number of sample sizes for 1 min data.

\begin{tabular}{lrrr}
\hline $\begin{array}{l}\text { Rainfall } \\
\text { category }\end{array}$ & $\begin{array}{r}\text { Total } \\
\text { precipitation }\end{array}$ & $\begin{array}{r}\text { Stratiform } \\
\text { precipitation (\%) }\end{array}$ & $\begin{array}{r}\text { Convective } \\
\text { precipitation }(\%)\end{array}$ \\
\hline Typhoon & 5095 & $3118(61.19)$ & $652(12.79)$ \\
Changma & 18526 & $11099(59.91)$ & $1611(8.69)$ \\
Heavy rainfall & 359 & $153(42.61)$ & $150(41.78)$ \\
Spring & 30703 & $20370(66.34)$ & $1478(4.81)$ \\
Summer & 37187 & $22566(60.68)$ & $3409(9.16)$ \\
Autumn & 19809 & $12033(60.74)$ & $850(4.29)$ \\
Winter & 11689 & $7582(64.86)$ & $339(2.90)$ \\
Daytime & 41328 & $26373(63.81)$ & $2539(6.14)$ \\
Nighttime & 37455 & $23063(84.00)$ & $2242(5.89)$ \\
Entire & 99388 & $62551(62.93)$ & $6076(6.11)$ \\
\hline
\end{tabular}

is higher at $>5.5$ than that of stratiform. There is a similar frequency in the stratiform and convective rainfall at 4.4 .

The PDF distributions for $\log _{10}(R)$ and $\log _{10}(\mathrm{LWC})$ are similar to each other (Fig. $4 \mathrm{~d}$ and e). It is inferred that the similar results come from the use of similar moments of DSD such as 3.67 and 3 for $R$ and LWC, respectively. The PDF of $\log _{10}(R)$ for the entire rainfall data set ranged between -0.5 and 2. A peak exists at 0.3 and the PDF rapidly decreases from the peak value as $R$ increases. The PDF for stratiform rainfall has a higher frequency than that of the entire rainfall when $-0.3<\log _{10}(R)<0.7$, while the PDF for convective rainfall is denser between 0.4 and 2 . Furthermore, the frequency of the PDF for convective rainfall was higher than that of stratiform rainfall in the case of $\log _{10}(R)>0.65$ and the peak value shown as 0.9 .

The PDF and CDF for $Z, Z_{\mathrm{dr}}, K_{\mathrm{dp}}$ and $A_{\mathrm{h}}$ are shown in Fig. $4 \mathrm{f}-\mathrm{i}$. The PDF of $Z$ for stratiform rainfall (Fig. $4 \mathrm{f}$ ) is widely distributed between 10 and $50 \mathrm{dBZ}$, with the peak at approximately $27 \mathrm{dBZ}$. Conversely, for convective rainfall, the values of PDF lie between 27 and $55 \mathrm{dBZ}$, and the peak frequency value at approximately $41 \mathrm{dBZ}$. The frequency value of reflectivity is higher for convective rainfall than for stratiform rainfall in the range of $\sim>35 \mathrm{dBZ}$. Furthermore, the shape of the PDF for convective rainfall is similar to that reported for Darwin, Australia (Steiner et al., 1995); however, for stratiform rainfall, there are significant differences between Busan and Darwin in terms of the shape of the frequency distribution. The PDF of $Z_{\mathrm{dr}}$ for the entire rainfall primarily exists between 0 and $2.5 \mathrm{~dB}$, and the peaks are at 0.3 and $1.8 \mathrm{~dB}$ (Fig. $4 \mathrm{~g}$ ). The distribution of $Z_{\mathrm{dr}}$ for convective and stratiform rainfall is concentrated between 0.6 and $1.6 \mathrm{~dB}$, and between 0.3 and $2 \mathrm{~dB}$, respectively. The frequency of $Z_{\mathrm{dr}}$ for convective (stratiform) rainfall exists in ranges higher (lower) than stratiform (convective) at $0.9 \mathrm{~dB}$.

The dominant distribution of $K_{\mathrm{dp}}$ for the entire data set and for stratiform rainfall lies between 0 and $0.14 \mathrm{deg} \mathrm{km}^{-1}$, with a peak value of 0.03 and $0.08 \mathrm{deg} \mathrm{km}^{-1}$. However, for convective rainfall, the PDF of $K_{\mathrm{dp}}$ evenly exists between 0.01 and $0.15 \mathrm{deg} \mathrm{km}^{-1}$. Furthermore, when
$K_{\mathrm{dp}}>0.056 \mathrm{deg} \mathrm{km}^{-1}$, the frequency of the PDF for convective rainfall is higher than that of stratiform rainfall (Fig. 4h).

The PDF of $A_{\mathrm{h}}$ is similar to that of $K_{\mathrm{dp}}$ and exists between 0 and $0.01 \mathrm{~dB} \mathrm{~km}^{-1}$. For the case of the entire rainfall data set and for stratiform rainfall, the PDF of $A_{\mathrm{h}}$ is concentrated between 0 and $2.0 \times 10^{-3} \mathrm{~dB} \mathrm{~km}^{-1}$ and that of convective rainfall is strongly concentrated between $1.0 \times 10^{-3}$ and $8.0 \times 10^{-3} \mathrm{~dB} \mathrm{~km}^{-1}$ (Fig. 4i). Unlike the PDF of $A_{\mathrm{h}}$ for convective rainfall, the PDF for stratiform rainfall shows a strong peak at about $7.0 \times 10^{-4} \mathrm{~dB} \mathrm{~km}^{-1}$.

\subsection{Climatological characteristics of DSD in Busan}

The climatological characteristics of DSDs for 10 rainfall categories are analyzed in this study. Sample size and ratio rainfall for each category are summarized in Table 3. Figure 5a illustrates the distribution of all $1 \mathrm{~min}$ stratiform rainfall data, and Fig. 5b shows scatter plots of averaged $D_{\mathrm{m}}$ and $\log _{10}\left(N_{\mathrm{w}}\right)$ for all 10 rainfall categories for stratiform rainfall data. Figure 5a displays a remarkable clear boundary in the bottom sector and shows that most of the data lie below the reference line used by Bringi et al. (2003) to classify convective and stratiform rainfall. The average values of $D_{\mathrm{m}}$ and $\log _{10}\left(N_{\mathrm{w}}\right)$ for all rainfall categories, except for heavy rainfall, exist between 1.4 and $1.6 \mathrm{~mm}$ and between 3.15 and 3.5, respectively (Fig. 5b). These values are relatively small compared with the reference line presented by Bringi et al. (2003).

The distribution of $1 \mathrm{~min}$ convective rainfall data is displayed in Fig. 6a, and the distribution of average values of $D_{\mathrm{m}}$ and $N_{\mathrm{w}}$ for the 10 rainfall categories in the case of convective rainfall in Fig. 6b. The blue and red plus symbols represent maritime and continental rainfall, respectively, as defined by Bringi et al. (2003). The scatter plot of 1 min convective rainfall data shows more in the continental cluster than the maritime cluster; however, the average values for the 10 rainfall categories are all located around the maritime cluster, except for the typhoon category. By considering the entire average values including typhoon events (Fig. 6b), we can induce the simple linear equation using $D_{\mathrm{m}}$ and $\log _{10}\left(N_{\mathrm{w}}\right)$ as follows:

$\log _{10}\left(N_{\mathrm{w}}\right)=-1.8 D_{\mathrm{m}}+6.9$.

Even the coefficients in Eq. (16) might be changed slightly with the typhoon values; this result is not present in $D_{\mathrm{m}}<1.2 \mathrm{~mm}$ and $D_{\mathrm{m}}>1.9 \mathrm{~mm}$. The $D_{\mathrm{m}}\left(N_{\mathrm{w}}\right)$ value for the typhoon category was considerably smaller (larger) than that of the other categories as well as that of the stratiform type of typhoon. This result does not agree with that reported by Chang et al. (2009), who noted that the $D_{\mathrm{m}}$ of convective rainfall typhoon showed a large value compared with that associated with stratiform rainfall. 

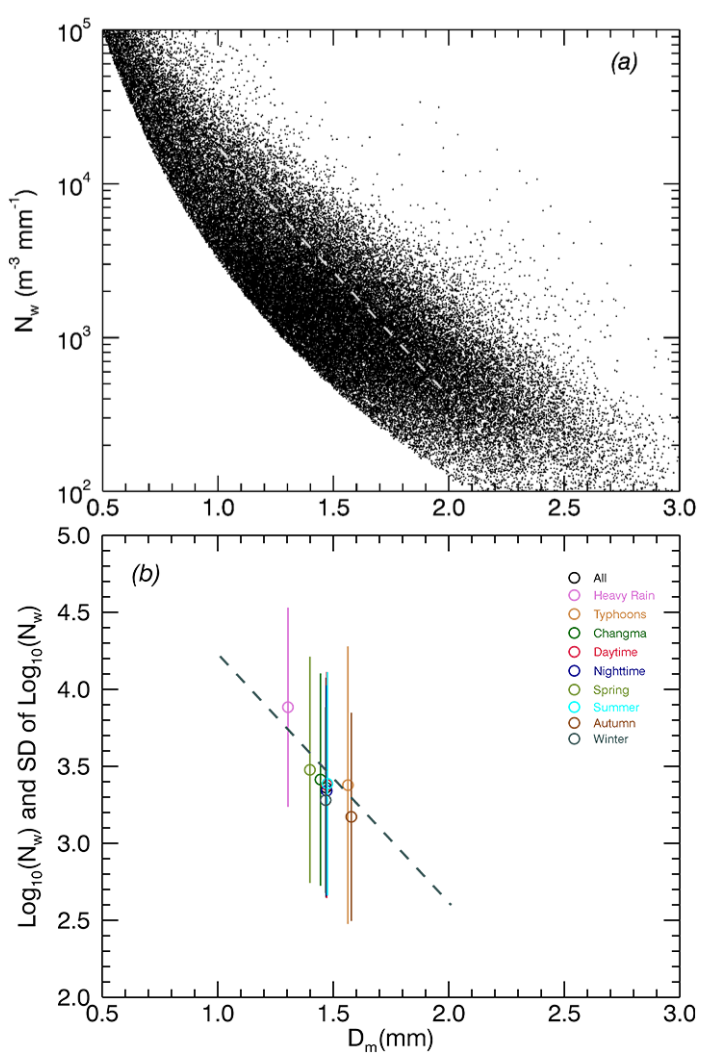

Figure 5. (a) Scatter plot of $1 \mathrm{~min} D_{\mathrm{m}}$ and $N_{\mathrm{w}}$ for the 10 rainfall categories with respect to stratiform rainfall data. The broken grey line represents the average line as defined by Bringi et al. (2003). (b) Scatter plot of mean $D_{\mathrm{m}}$ and $\log _{10}\left(N_{\mathrm{W}}\right)$ values of the 10 rainfall categories with respect to stratiform rainfall; these mean values for each rainfall type are shown as circle symbols. The vertical line represents $\pm 1 \sigma$ of $\log _{10}\left(N_{\mathrm{W}}\right)$ for each category.

\subsection{Diurnal variation in raindrop size distributions}

\subsubsection{Diurnal variations in DSDs}

Figure 7a shows a histogram of normalized frequency of 16 wind directions recorded by the AWS, which is the same instrument as that used to collect the data shown in Fig. 3. To establish the existence of a land and sea wind, the difference in wind direction frequencies between DT and NT were analyzed. Figure $7 \mathrm{~b}$ shows the difference between DT and NT; difference frequency means normalized frequency of wind direction for DT subtracted from that of NT for each direction, in terms of the normalized frequency of 16 wind directions. In other words, positive (negative) values indicate that the frequency of wind is more often observed during DT (NT). Also, land (sea) wind was defined in the present study from $225^{\circ}\left(45^{\circ}\right)$ to $45^{\circ}\left(225^{\circ}\right)$ according to the geographical condition in Busan. The predominant frequency of wind direction in DT (NT), between $205^{\circ}\left(22.5^{\circ}\right)$ and $22.5^{\circ}$ $\left(205.5^{\circ}\right)$, is higher than that in NT (DT) (Fig. 7b). The ob-
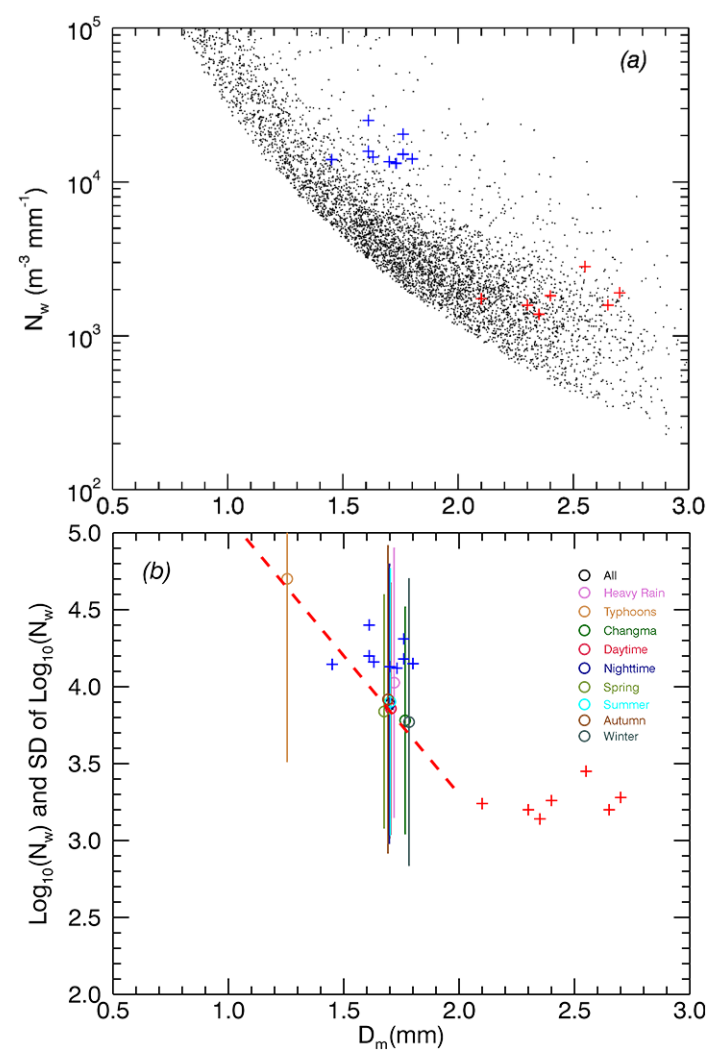

Figure 6. (a) As in Fig. 5a but for convective rainfall. The blue and red plus symbols represent maritime and continental rainfall, respectively, as defined by Bringi et al. (2003). (b) As in Fig. 5 b but for convective rainfall. The broken red line represents the mathematical expression described in Eq. (16).

servation site distance where the POSS was installed at the western side from the closest coastline is about $611 \mathrm{~m}$, suggesting that the effect of the land and sea wind would have been recorded. To understand the effects of the land and sea wind on DSD characteristics, we analyzed the PDF and $2 \mathrm{~h}$ averaged DSD parameters for DT and NT. Figure 8 illustrates the distributions of $\mu, D_{\mathrm{m}}, \log _{10}\left(N_{\mathrm{w}}\right), \log _{10}(\mathrm{LWC})$, $\log _{10}(R)$, and $Z$. There were large variations of $\mu$ with time. The $\mu$ values varied from 2.41 to 3.17 , and the minimum and maximum $\mu$ values occurred at 08:00 and 12:00 KST, respectively (Fig. 8a). A $D_{\mathrm{m}}$ larger than $1.3 \mathrm{~mm}$ dominated from 00:00 to 12:00 KST, before decreasing remarkably between 12:00 and 14:00 KST. The minimum and maximum $D_{\mathrm{m}}$ appeared at 14:00 and 08:00 KST, respectively (Fig. 8b).

The $N_{\mathrm{w}}$ distribution showed inversely to $D_{\mathrm{m}}$; however, no inverse relationship was identified between $D_{\mathrm{m}}$ and $N_{\mathrm{w}}$ in the case of the time series (Fig. 8c). The maximum and minimum values of $N_{\mathrm{w}}$ were found at 06:00 and 22:00 KST.

Variability through time was similar for $R$, LWC, and $Z_{\mathrm{h}}$ like $D_{\mathrm{m}}$. There was an increasing trend from 00:00 to 08:00 KST followed by a remarkably decreasing trend from 08:00 to 14:00 KST (Figs. 8d, 11e and 11f). Note that the 

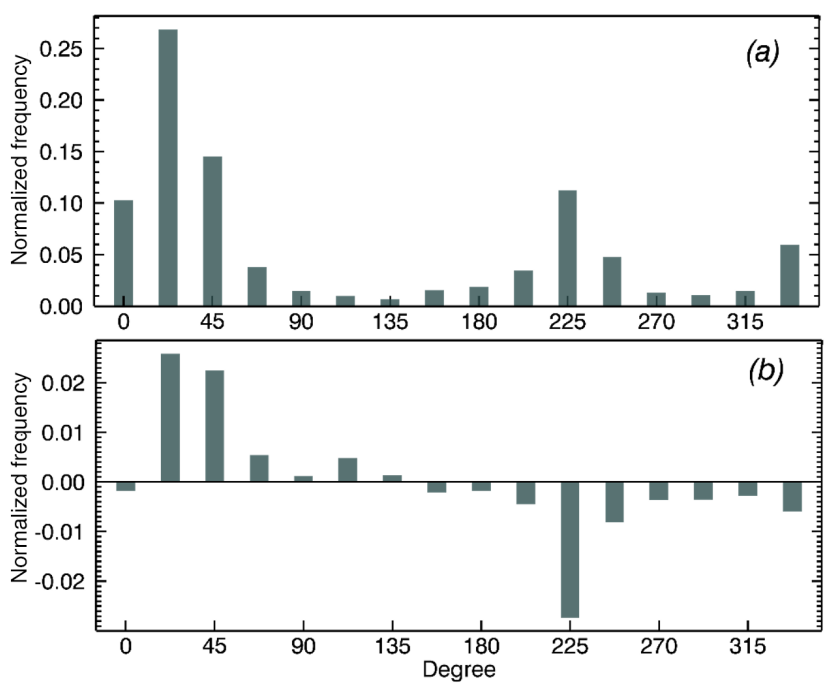

Figure 7. (a) Histogram of normalized frequency of 16 wind directions for the entire study period. (b) Difference values of wind direction frequencies between DT and NT (DT-NT).

time of the sharp decline for $R$ between 12:00 and 14:00 KST is simultaneous with a $D_{\mathrm{m}}$ decrease. Larger (smaller) drops would contribute to higher $R$ in the morning (afternoon). These variations considerably matched with the diurnal sea wind time series (Fig. 8g). Sea wind is the sum value of normalized wind frequency between 45 and $225^{\circ}$. From 02:00 (14:00) to 12:00 (20:00) KST, Fig. 8g shows a smaller (larger) value of sea wind frequency, which is opposite to the relatively larger (smaller) parts of each parameter $\left(D_{\mathrm{m}}, R\right.$, LWC and $Z_{\mathrm{h}}$ ).

The PDF distribution of $\mu$ between -2 and 0 is more concentrated for NT than for DT. Furthermore, when $\mu>0$, DT and NT frequency distributions are similar (Fig. 9a). A larger $N(D)$ of small or large raindrops would be expected in NT than in DT.

The distribution of DT $D_{\mathrm{m}}<0.7 \mathrm{~mm}$ is wider than that of NT. However, between 0.7 and $1.5 \mathrm{~mm}$, the frequency for NT is higher than that for DT, whereas the distribution in the range $D_{\mathrm{m}}>1.5 \mathrm{~mm}$ is similar for both DT and NT (Fig. 9b). We note that the smaller peak of $D_{\mathrm{m}}$ around $0.6 \mathrm{~mm}$ for the entire rainfall data set (Fig. 4b) was observed only in DT.

The distribution of $\log _{10}\left(N_{\mathrm{w}}\right)$ for DT has a higher value of PDF at larger $\log _{10}\left(N_{\mathrm{w}}\right)$ than that of NT at $\log _{10}\left(N_{\mathrm{w}}\right)>4$ (Fig. 9c).

Bringi et al. (2003) noted that the maritime climatology displayed larger $N_{\mathrm{w}}$ and smaller $D_{\mathrm{m}}$ values than the continental climatology, based on observed DSDs in the low and middle latitudes. Also, Göke et al. (2007) emphasized that rainfall type can be defined by the origin location and movement direction. In accordance with these previous results, we consider NT rainfall in the Busan region to be more likely caused by a continental convective system.
Table 4. DT and NT (KST) in the summer and winter seasons.

\begin{tabular}{lccc}
\hline $\begin{array}{l}\text { Rainfall } \\
\text { category }\end{array}$ & Period & $\begin{array}{c}\text { Beginning time } \\
(\text { KST })\end{array}$ & $\begin{array}{c}\text { Finishing time } \\
(\text { KST })\end{array}$ \\
\hline \multirow{2}{*}{ Summer } & DT & $05: 33$ & $19: 27$ \\
& NT & $19: 42$ & $05: 09$ \\
\multirow{2}{*}{ Winter } & DT & $07: 33$ & $17: 12$ \\
& NT & $18: 19$ & $06: 54$ \\
\hline
\end{tabular}

In the present study, the shape of the PDF of LWC and $R$ for DT and NT are similar, which is the same reason with the results of Fig. 4e-f. LWC and $R$ distributions during DT (NT) are higher (lower) than in NT (DT) when $\log _{10}(\mathrm{LWC})$ and $\log _{10}(R)$ are larger (smaller) than -1.2 and 0 , respectively (Fig. 9d and e). Z has a similar pattern with LWC, and $R$ during DT (NT) was higher (lower) than in NT (DT) in the range below (above) about $27 \mathrm{dBZ}$ (Fig. 9f).

\subsubsection{Diurnal variations of DSDs with respect to season}

Busan experiences distinct atmospheric conditions that are caused by the different frequencies and magnitudes of land and sea winds in response to variable sunrise and sunset times. To identify seasonal variations of DSDs with respect to the effect of the land and sea wind, we analyzed the DT and NT PDF of $D_{\mathrm{m}}$ and $N_{\mathrm{w}}$ in the summer and winter. The start and end times of DT (NT) were sorted using the latest sunrise (sunset) and the earliest sunset (sunrise) time for each season (Table 4), which is the same method as that of the entire period of classification.

Figure 10a shows a histogram of wind directions in summer (light grey) and winter (dark grey). The frequencies of summer and winter wind directions are similar to each other. However, in Fig. 10b, the DT and NT distributions of winter wind direction display opposite frequencies.

Note that the winter season shows remarkable frequency of land (sea) wind between $0^{\circ}\left(157.5^{\circ}\right)$ and $45^{\circ}\left(202.5^{\circ}\right)$ at DT (NT) compared with results of those for the summer season. The accumulated value of normalized wind frequencies at the sea and land wind show different features between the summer and winter seasons (Table 5).

To identify the variability of DSDs caused by the land and sea wind in summer and winter, a $2 \mathrm{~h}$ interval time series of $D_{\mathrm{m}}, N_{\mathrm{w}}$ and $R$ was analyzed. In the summer, the time series of $D_{\mathrm{m}}$ displays considerably large values between 00:00 and 12:00 KST, compared with the period between 14:00 and 22:00 KST (Fig. 11a). The mean value of $D_{\mathrm{m}}$ decreases dramatically between 12:00 and 14:00 KST. $\log _{10}\left(N_{\mathrm{w}}\right)$ has a negative relationship with $D_{\mathrm{m}}$ (Fig. 11b). However, the inverse relation between $\log _{10}\left(N_{\mathrm{w}}\right)$ and $D_{\mathrm{m}}$ is not remarkable. $\log _{10}(R)$ tends to increase gradually from 00:00 to 08:00 KST and decrease from 08:00 to 14:00 KST, which is similar to the pattern of that of the entire period (Fig. 11c). Kozu et al. (2006) analyzed the diurnal variation in $R$ at 

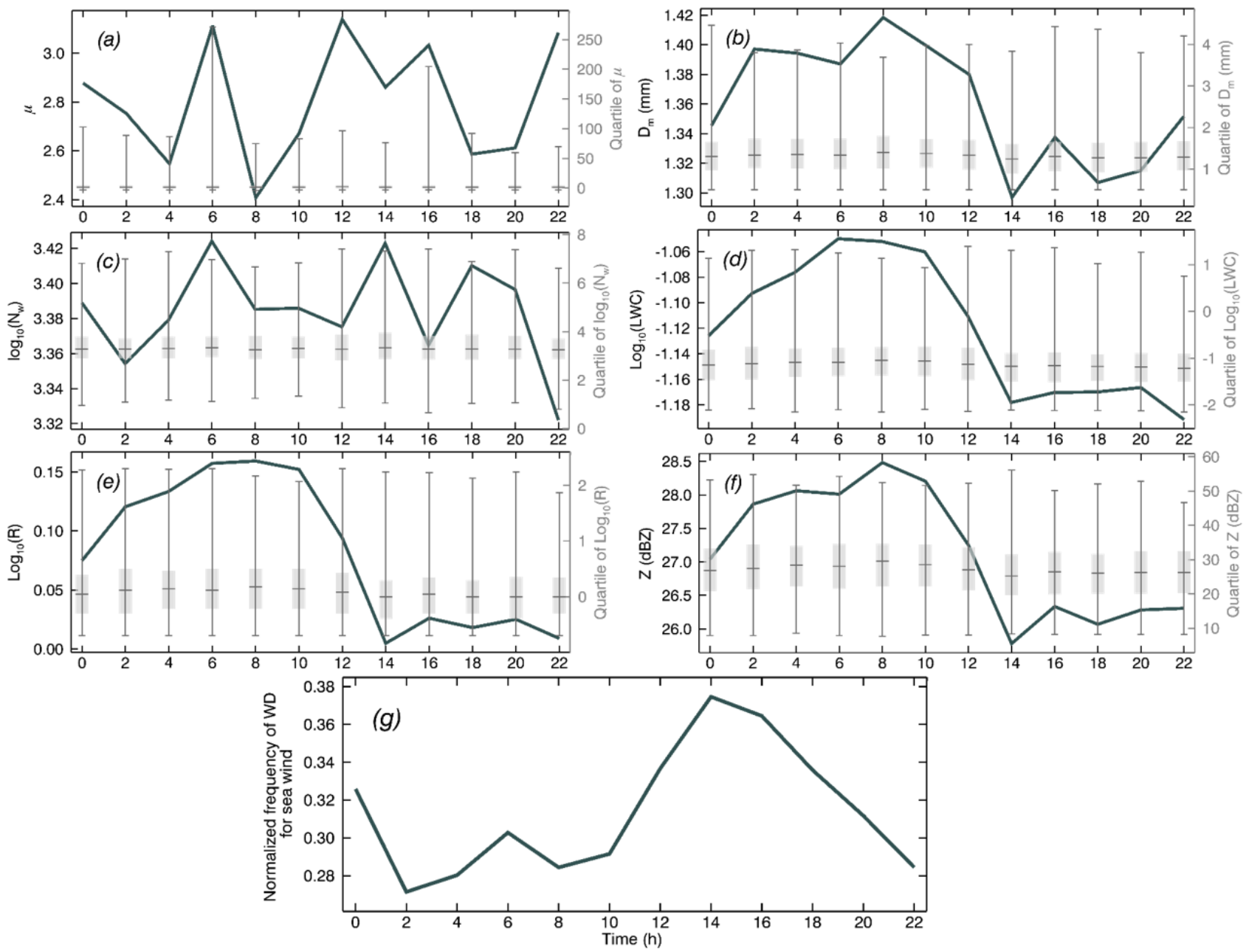

Figure 8. Two-hour interval time series of (a) $\mu$, (b) $D_{\mathrm{m}}$, (c) $\log _{10}\left(N_{\mathrm{W}}\right),(\mathbf{d}) \log _{10}(R),(\mathbf{e}) \log _{10}(\mathrm{LWC})$, (f) $Z_{\mathrm{h}}$, and (g) normalized frequency of wind direction for sea wind $\left(45\right.$ to $\left.225^{\circ}\right)$ with quartiles for the total period. Solid lines are quartiles for each time.

Table 5. Sum of the normalized wind direction frequencies between summer and winter.

\begin{tabular}{lclll}
\hline \multicolumn{4}{c}{ Sum of the normalized wind direction frequencies } \\
\hline $\begin{array}{l}\text { Season } \\
\text { Type }\end{array}$ & Sea wind & Land wind & Sea wind & Land wind \\
Frequency & 0.4139 & 0.5861 & 0.3137 & 0.6863 \\
\hline \multicolumn{5}{c}{ Difference of the normalized wind direction frequency between } \\
\multicolumn{5}{c}{ DT and NT (DT-NT) } \\
\hline Season & \multicolumn{3}{c}{ Summer } & \multicolumn{2}{c}{ Winter } \\
Type & Sea wind & Land wind & Sea wind & Land wind \\
Frequency & 0.0731 & -0.0731 & -0.0697 & 0.0697 \\
\hline
\end{tabular}

Gadanki (southern India), Singapore, and Kototabang (West Sumatra) during the summer monsoon season. All regions displayed maximum $R$ at approximately 16:00 LST, except for Gadanki. Also, Qian (2008) analyzed the diurnal variability of wind direction and $R$ on Java during the summer season using 30 years (from 1971 to 2000) of NCEP/NCAR reanalyzed data. They found that a land wind occurred from 01:00 to 10:00 LST and a sea wind from 13:00 to 22:00 LST (Fig. 7 of Qian, 2008). Normalized wind frequency for each direction is a similar pattern to the results of Qian (2008), but the pattern of $R$ is different from that of Kozu et al. (2006). The diurnal variation of rain rate in the present study from 02:00 (12:00) to 10:00 (20:00) KST shows relatively smaller (larger) frequencies of sea wind. It is a different pattern from the result of Kozu et al. (2006). However, these patterns matched with the time series of $D_{\mathrm{m}}$ and $\log _{10}\left(N_{\mathrm{w}}\right)$. A larger frequency of sea wind direction shows a counter-proportional (proportional) relationship to the smaller (larger) frequency of $D_{\mathrm{m}}\left(\log _{10}\left(N_{\mathrm{w}}\right)\right)$.

Variability of the $D_{\mathrm{m}}$ time series for winter is the inverse of the summer time series (Fig. 11a). The mean value of $D_{\text {m }}$ steadily increases from 00:00 to 16:00 KST and then decreases from 16:00 to 22:00 KST. The winter $\log _{10}\left(N_{\mathrm{w}}\right)$ time series displays a clear inverse pattern compared with 

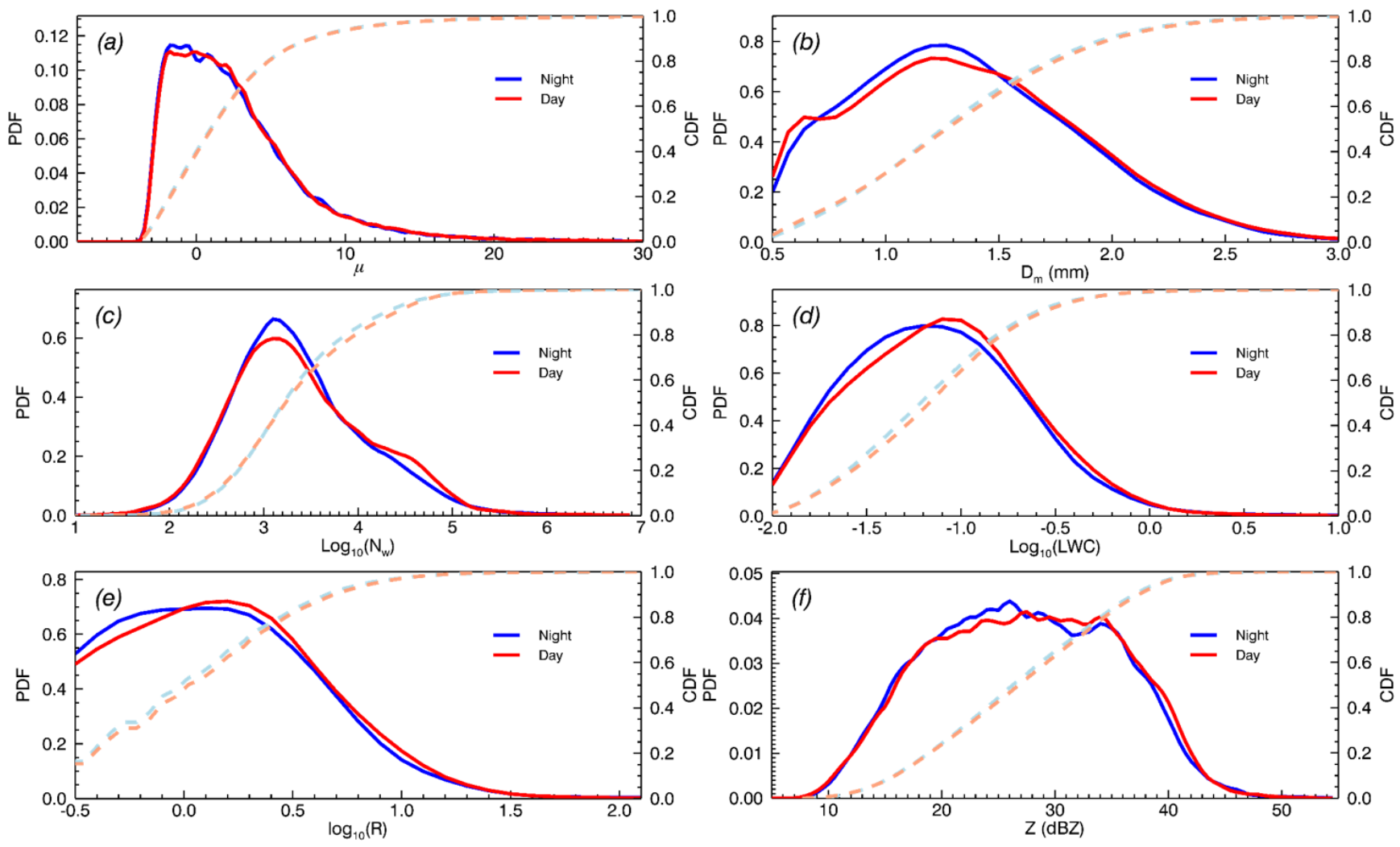

Figure 9. PDF and CDF curves for (a) $\mu$, (b) $D_{\mathrm{m}}$, (c) $\log _{10}\left(N_{\mathrm{W}}\right),(\mathbf{d}) \log _{10}(R)$, (e) $\log _{10}$ (LWC), and (f) $Z$ for DT and NT according to the entire period. The solid red and blue lines represent the PDF for DT and NT, respectively. The broken light red and blue lines represent the CDF for DT and NT, respectively.
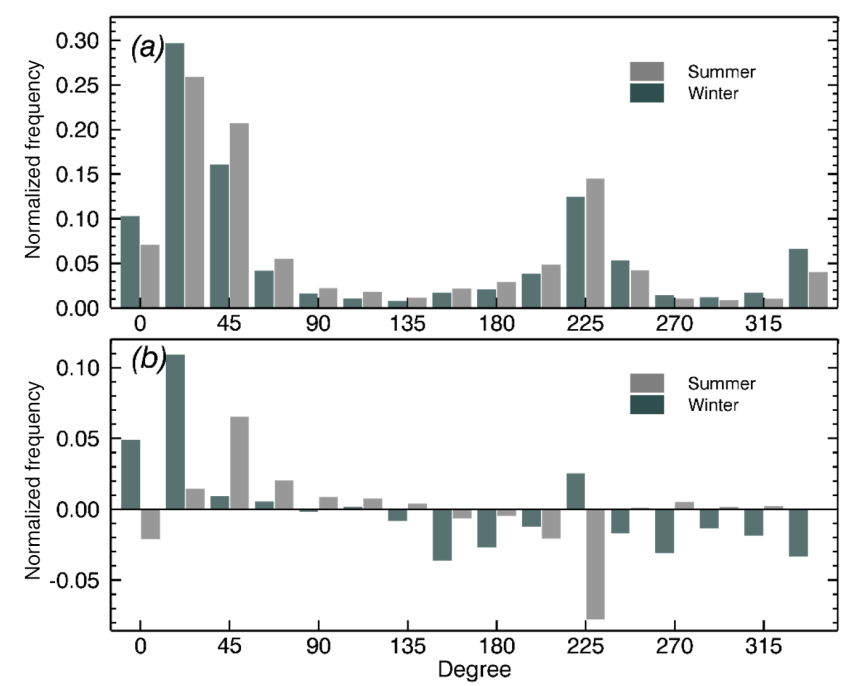

Figure 10. Histogram of normalized frequency for 16 wind directions in (a) the entire period and (b) differences of normalized frequency with respect to wind directions between DT and NT (DTNT) for the summer (light grey) and winter (dark grey) seasons. the $D_{\mathrm{m}}$ variation with time and increases from 16:00 KST to $04: 00 \mathrm{KST}$ and then steadily decreases from 04:00 to 16:00 KST (Fig. 11b). The peak of $\log _{10}\left(N_{\mathrm{w}}\right)$ occurs at 04:00 KST. However, the time series of $\log _{10}(R)$ for the winter season shows a similar pattern to that of summer, unlike other parameters (Fig. 11c). Based on the diurnal variation of $R$, the variations of $D_{\mathrm{m}}$ and $N_{\mathrm{w}}$ would be independent of $R$.

Similar to $D_{\mathrm{m}}$ and $\log _{10}\left(N_{\mathrm{w}}\right)$, normalized wind frequency of wind direction for the winter season shows an inverse relationship with that of the summer season (Fig. 11d). The value of the frequency generally decreases (increases) from 04:00 (14:00) to $14: 00(04: 00) \mathrm{KST}$. Also, it shows a symmetry pattern with that of the summer season.

The PDF distribution of summer $D_{\mathrm{m}}$ displays a relatively large DT frequency compared with NT when $D_{\mathrm{m}}<1.65 \mathrm{~mm}$, except for the range between 0.6 and $0.9 \mathrm{~mm}$. However, in the range of $D_{\mathrm{m}}>1.65 \mathrm{~mm}$, the NT PDF displays a larger frequency (Fig. 12a). The PDF of $\log _{10}\left(N_{\mathrm{w}}\right)$ for DT (NT) has a larger frequency than NT (DT) when $\log _{10}\left(N_{\mathrm{w}}\right)>(<) 3.3$, but a smaller frequency when $\log _{10}\left(N_{\mathrm{w}}\right)<(>) 3.3$ (Fig. 12c).

The DT and NT PDFs of $D_{\mathrm{m}}$ and $\log _{10}\left(N_{\mathrm{w}}\right)$ during winter display an inverse distribution to that of summer. For the PDF of $D_{\mathrm{m}}$, there is a considerable frequency for NT (DT) when $D_{\mathrm{m}}<(>) 1.6 \mathrm{~mm}$ (Fig. 12b). The PDF of $\log _{10}\left(N_{\mathrm{w}}\right)$ 

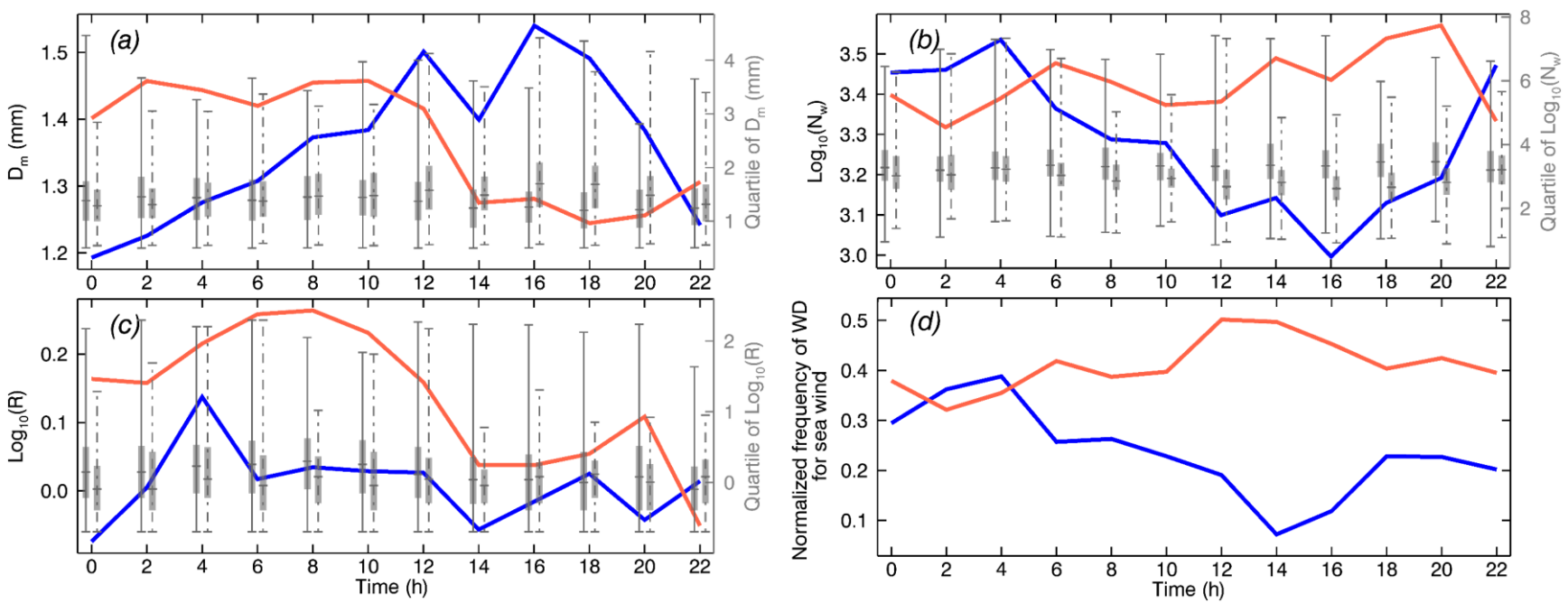

Figure 11. Two-hour interval time series and quartiles of (a) $D_{\mathrm{m}}$, (b) $\log _{10},\left(N_{\mathrm{W}}\right)$ (c) $\log _{10}(R)$, and (d) normalized frequency of wind direction for sea wind $\left(45\right.$ to $225^{\circ}$ ) for the summer (red) and winter (blue) seasons. Solid (broken) lines are quartiles of summer (winter) for each time, respectively.
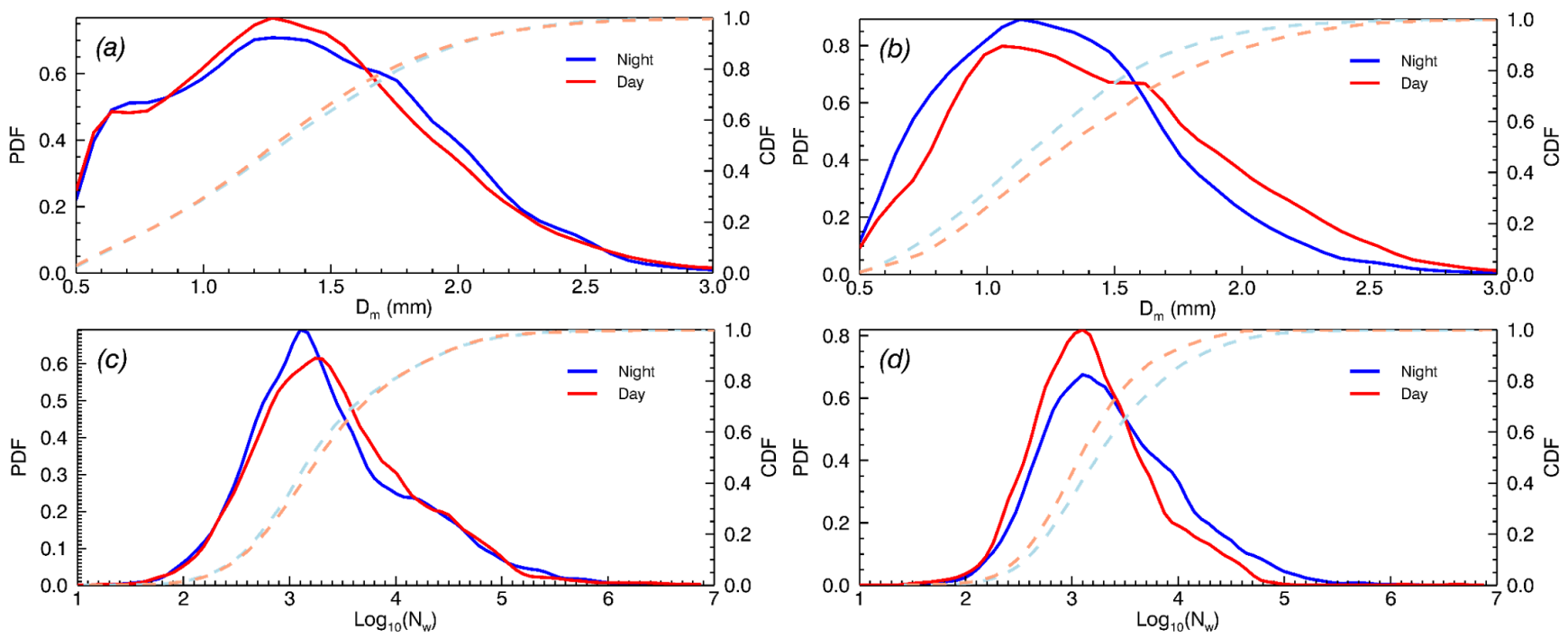

Figure 12. PDF and CDF of (a) $D_{\mathrm{m}}\left((\mathbf{b}) D_{\mathrm{m}}\right)$ and (c) $N_{\mathrm{W}}\left((\mathbf{d}) N_{\mathrm{W}}\right)$ for all rainfall types in the summer (winter) season. Red and blue solid lines represent the PDF of DT and NT, respectively. The light red and blue broken lines represent the CDF for each season.

of the summer season for NT (DT) is larger than that of DT when $\log _{10}\left(N_{\mathrm{w}}\right)<(>) 3.5$ (Fig. 12d). In the PDF analysis, relatively large (small) $D_{\mathrm{m}}$ and small (large) $\log _{10}\left(N_{\mathrm{w}}\right)$ are displayed during NT (DT) when a land wind (sea wind) occurs.

Bringi et al. (2003) referred to the fact that the convective rainfall type is able to be classified as the continental and maritime-like precipitation using $\mathrm{D}_{\mathrm{m}}$ and $N_{\mathrm{w}}$. As the previous study result, we analyzed the PDF of DSDs for summer and winter with respect to convective rainfall type. These feature would be shown more clearly in the convective type. The convective rainfall type of PDFs of DT and
NT for summer show a similar shape of distribution to that of all rainfall types (Fig. 3a). For the PDF of $D_{\mathrm{m}}$, there is a higher frequency for DT (NT) than NT (DT) when $D_{\mathrm{m}}$ <(>) $2.0 \mathrm{~mm}$, except for between 0.7 and $1.2 \mathrm{~mm}$ (Fig. 13a). The PDF of convective rainfall type $\log _{10}\left(N_{\mathrm{w}}\right)$ for DT (NT) has a larger frequency than NT (DT) when $\log _{10}\left(N_{\mathrm{w}}\right)>(<)$ 3.4, except for between 4.3 and 5.5 (Fig. 12c). PDF distributions for the winter season show a clearer pattern compared with those of the entire rainfall type. The values of PDF for $D_{\mathrm{m}}$ in DT (NT) are considerably larger than NT (DT) when $D_{\mathrm{m}}>(<) 1.9 \mathrm{~mm}$, especially between 2.15 and $2.3 \mathrm{~mm}$ (Fig. 13b). Also, those for $\log _{10}\left(N_{\mathrm{w}}\right)$ in DT (NT) 

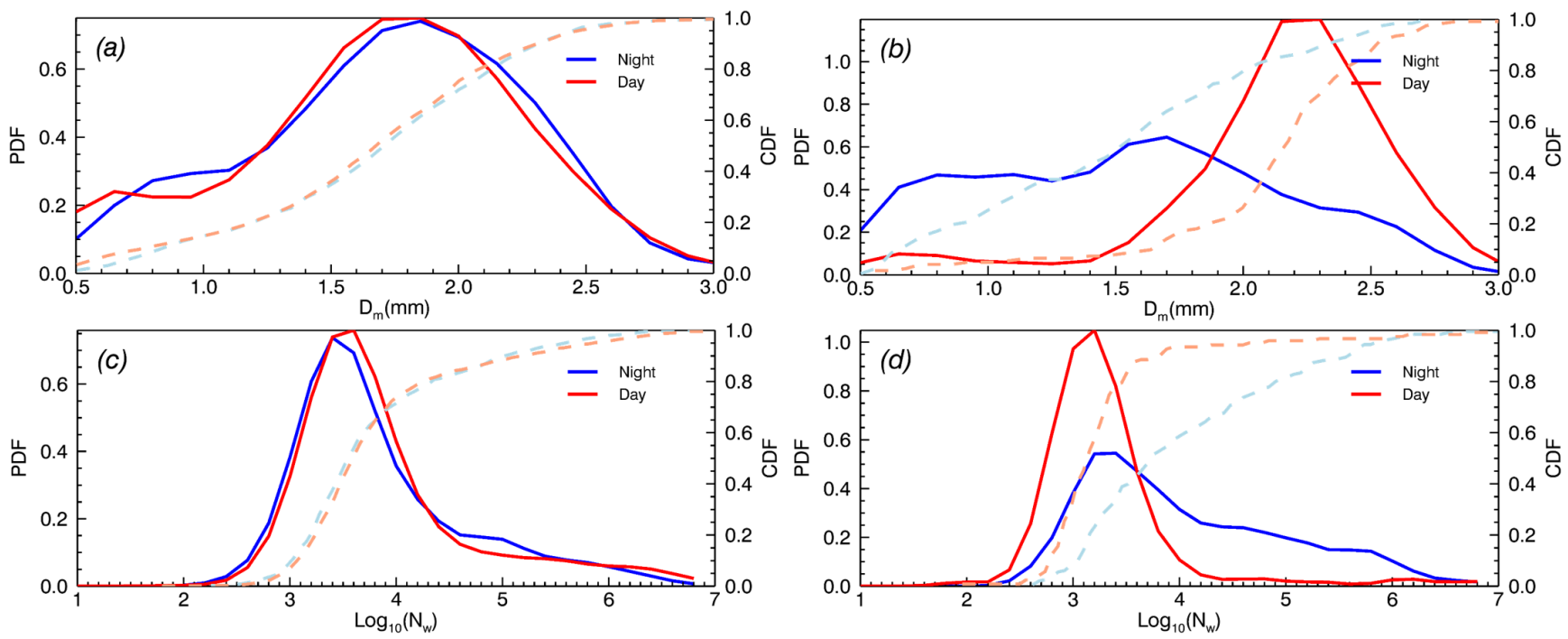

Figure 13. As in Fig. 12 but for convective rainfall type.

show dramatic values when $\log _{10}\left(N_{\mathrm{w}}\right)<(>)$ 3.6. Furthermore, PDF values were significantly concentrated between $3<\log _{10}\left(N_{\mathrm{w}}\right)<3.2$ (Fig. 13d). In short, considering the DSD parameters with wind directions, the maritime (continental)like precipitation would depend on the sea (land) wind.

\section{Summary and conclusion}

Climatological characteristics of DSDs in Busan were analyzed using the DSD data observed by POSS over a 4-year period from 24 February 2001 to 24 December 2004. Observed DSDs were filtered to remove errors by performing several quality control measures, and an AWS rain gauge installed nearby was used to verify the rainfall amount recorded by the POSS. We analyzed DSD characteristics of convective and stratiform rainfall types, as defined by Bringi et al. (2003). The rainfall data set was thus divided into stratiform and convective rainfall and their contributions to the total rainfall were 62.93 and $6.11 \%$, respectively. Also, to find the climatological characteristics of DSD for the rainfall case, the entire rainfall data were classified as 10 rainfall categories including the entire period case.

According to the study by Bringi et al. (2003), the rainfall in Busan shows maritime climatological DSD characteristics. The mean values of $D_{\mathrm{m}}$ and $N_{\mathrm{w}}$ for stratiform rainfall are relatively small compared with the average line of stratiform rainfall produced by Bringi et al. (2003), except for heavy rainfall events. In the case of convective type, mean values of $\mathrm{D}_{\mathrm{m}}$ and $N_{\mathrm{w}}$ are converged around the maritime cluster, except for the typhoon category. The convective rainfall associated with a typhoon has considerably smaller $D_{\mathrm{m}}$ and larger $N_{\mathrm{w}}$ values compared with the other rainfall categories. This is likely caused by an increased raindrop breakup mechanism as a result of strong wind effects. Further- more, the distributions of mean $D_{\mathrm{m}}$ and $N_{\mathrm{w}}$ values for all rainfall categories associated with convective rainfall display a linear relationship including the typhoon category.

The analysis of diurnal variation in DSD yielded the following results: first, the frequency of $\mu$ is higher at NT than during DT in the negative value. The PDF of $R$ is higher at NT than during DT when $\log _{10}(R)>0.6$. The value of PDF for $D_{\mathrm{m}}$ during DT is larger than NT smaller than $0.65 \mathrm{~mm}$. For $N_{\mathrm{w}}$, which tends to be inversely related to $D_{\mathrm{m}}$, its frequency is higher at NT than DT when $\log _{10}\left(\mathrm{~N}_{\mathrm{w}}\right)>3.8$. This feature is matched with the time series of normalized frequency of sea wind, which shows an inverse relationship with $D_{\mathrm{m}}$. Smaller $D_{\mathrm{m}}$ corresponds to the larger sea wind frequency. In short, maritime (continental)-like precipitation is observed in DT (NT) more often than in NT (DT) according to the features of wind. The above-mentioned DSD characteristics are likely due to the land and sea wind caused by differences in specific heat between the land and ocean. These features are also apparent in the seasonal diurnal distribution. The PDF of DT and NT for convective rainfall type during the summer is similar to the PDF of the entire period; however, those of the winter display the significant inverse distribution compared to the summer because of obvious seasonal differences in wind direction.

Author contributions. C.-H. You designed the study. S.-H. Suh modified the original study theme and performed the study. C.H. You and S.-H. Suh performed research, obtained the results and prepared the manuscript along with contributions from all of the coauthors. D.-I. Lee examined the results and checked the manuscript. 
Acknowledgements. This work was funded by the Korea Meteorological Industry Promotion Agency under grant KMIPA 2015-1050. The authors acknowledge provision of the weather chart and AWS data for this work from the Korea Meteorological Administration, and codes for scattering simulation from V. N. Bringi at Colorado State University.

Edited by: M. Mikos

\section{References}

Andsager, K., Beard, K. V., and Laird, N. F.: Laboratory measurements of axis ratios for large raindrops, J. Atmos. Sci., 56, 26732683, 1999.

Atlas, D., Srivastava, R., and Sekhon, R. S.: Doppler radar characteristics of precipitation at vertical incidence, Rev. Geophys., 11, $1-35,1973$.

Atlas, D., Ulbrich, C. W., Marks, F. D., Amitai, E., and Williams, C. R.: Systematic variation of drop size and radar-rainfall relations, J. Geophys. Res.-Atmos., 104, 6155-6169, 1999.

Beard, K. V. and Chuang, C.: A new model for the equilibrium shape of raindrops, J. Atmos. Sci., 44, 1509-1524, 1987.

Brandes, E. A., Zhang, G., and Vivekanandan, J.: Experiments in rainfall estimation with a polarimetric radar in a subtropical environment, J. Appl. Meteorol., 41, 674-685, 2002.

Bringi, V., Chandrasekar, V., Hubbert, J., Gorgucci, E., Randeu, W., and Schoenhuber, M.: Raindrop size distribution in different climatic regimes from disdrometer and dual-polarized radar analysis, J. Atmos. Sci., 60, 354-365, 2003.

Chang, W.-Y., Wang, T.-C. C., and Lin, P.-L.: Characteristics of the raindrop size distribution and drop shape relation in Typhoon systems in the western Pacific from the 2D video disdrometer and NCU C-band polarimetric radar, J. Atmos. Ocean. Tech., 26, 1973-1993, 2009.

Dou, X., Testud, J., Amayenc, P., and Black, R.: The parameterization of rain for a weather radar, Comptes Rendus de l'Académie des Sciences-Series IIA-Earth and Planetary Science, 328, $577-$ $582,1999$.

Feingold, G. and Levin, Z.: The lognormal fit to raindrop spectra from frontal convective clouds in Israel, J. Clim. Appl. Meteorol., 25, 1346-1363, 1986.

Gamache, J. F. and Houze Jr., R. A.: Mesoscale air motions associated with a tropical squall line, Mon. Weather Rev., 110, 118$135,1982$.

Göke, S., Ochs III, H. T., and Rauber, R. M.: Radar analysis of precipitation initiation in maritime versus continental clouds near the Florida coast: Inferences concerning the role of $\mathrm{CCN}$ and giant nuclei, J. Atmos. Sci., 64, 3695-3707, 2007.

Gunn, R. and Kinzer, G. D.: The terminal velocity of fall for water droplets in stagnant air, J. Meteorol., 6, 243-248, 1949.

$\mathrm{Hu}, \mathrm{Z}$. and Srivastava, R.: Evolution of raindrop size distribution by coalescence, breakup, and evaporation: Theory and observations, J. Atmos. Sci., 52, 1761-1783, 1995.

Johnson, R. H. and Hamilton, P. J.: The relationship of surface pressure features to the precipitation and airflow structure of an intense midlatitude squall line, Mon. Weather Rev., 116, 1444$1473,1988$.
Kozu, T., Reddy, K. K., Mori, S., Thurai, M., Ong, J. T., Rao, D. N., and Shimomai, T.: Seasonal and diurnal variations of raindrop size distribution in Asian monsoon region, J. Meteorol. Soc. Jpn., 84, 195-209, 2006.

Leinonen, J., Moisseev, D., Leskinen, M., and Petersen, W. A.: A climatology of disdrometer measurements of rainfall in Finland over five years with implications for global radar observations, J. Appl. Meteorol. Clim., 51, 392-404, 2012.

Levin, Z.: Charge separation by splashing of naturally falling raindrops, J. Atmos. Sci., 28, 543-548, 1971.

Mapes, B. E. and Houze Jr., R. A.: Cloud clusters and superclusters over the oceanic warm pool, Mon. Weather Rev., 121, 13981416, 1993.

Markowitz, A. H.: Raindrop size distribution expressions, J. Appl. Meteorol., 15, 1029-1031, 1976.

Marshall, J. S. and Palmer, W. M. K.: The distribution of raindrops with size, J. Meteorol., 5, 165-166, 1948.

Mueller, E. A. and Sims, A. L.: Radar cross sections from drop size spectra, Tech. Rep. ECOM-00032-F, Contract DA-28-043 AMC-00032(E), Illinois State Water Survey, Urbana, 110 pp., AD-645218, 1966.

Pruppacher, H. and Beard, K.: A wind tunnel investigation of the internal circulation and shape of water drops falling at terminal velocity in air, Q. J. Roy. Meteor. Soc., 96, 247-256, 1970.

Qian, J.-H.: Why precipitation is mostly concentrated over islands in the Maritime Continent, J. Atmos. Sci., 65, 1428-1441, 2008.

Ray, P. S.: Broadband complex refractive indices of ice and water, Appl. Optics, 11, 1836-1844, 1972.

Sauvageot, H. and Lacaux, J.-P.: The shape of averaged drop size distributions, J. Atmos. Sci., 52, 1070-1083, 1995.

Seliga, T. and Bringi, V.: Potential use of radar differential reflectivity measurements at orthogonal polarizations for measuring precipitation, J. Appl. Meteorol., 15, 69-76, 1976.

Sheppard, B. E.: Measurement of raindrop size distributions using a small Doppler radar, J. Atmos. Ocean. Tech., 7, 255-268, 1990.

Sheppard, B. E. and Joe, P. I.: Comparison of raindrop size distribution measurements by a Joss-Waldvogel disdrometer, a PMS 2DG spectrometer and a POSS Doppler radar, J. Atmos. Ocean. Tech., 11, 874-887, 1994.

Sheppard, B. and Joe, P.: Performance of the precipitation occurrence sensor system as a precipitation gauge, J. Atmos. Ocean. Tech., 25, 196-212, 2008.

Steiner, M., Houze Jr., R. A., and Yuter, S. E.: Climatological characterization of three-dimensional storm structure from operational radar and rain gauge data, J. Appl. Meteorol., 34, 19782007, 1995.

Testud, J., Oury, S., Black, R. A., Amayenc, P., and Dou, X.: The concept of "normalized" distribution to describe raindrop spectra: A tool for cloud physics and cloud remote sensing, J. Appl. Meteorol., 40, 1118-1140, 2001.

Tokay, A. and Short, D. A.: Evidence from tropical raindrop spectra of the origin of rain from stratiform versus convective clouds, J. Appl. Meteorol., 35, 355-371, 1996.

Ulbrich, C. W.: Natural variations in the analytical form of the raindrop size distribution, J. Clim. Appl. Meteorol., 22, 1764-1775, 1983.

Ulbrich, C. W. and Atlas, D.: Rainfall microphysics and radar properties: Analysis methods for drop size spectra, J. Appl. Meteorol., 37, 912-923, 1998. 
Waterman, P. C.: Matrix formulation of electromagnetic scattering, Proc. IEEE, 53, 805-812, 1965.

Waterman, P. C.: Symmetry, unitarity, and geometry in electromagnetic scattering, Phys. Rev. D, 3, 825-839, 1971.

Willis, P. T.: Functional fits to some observed drop size distributions and parameterization of rain, J. Atmos. Sci., 41, 1648$1661,1984$.
You, C.-H., Lee, D.-I., and Kang, M.-Y.: Rainfall estimation using specific differential phase for the first operational polarimetric radar in Korea, Advances in Meteorology, 1-10, doi:10.1155/2014/413717, 2014. 